\title{
ENERGY TRANSFER IN ONE-, TWO-, AND THREE-DIMENSIONALLY COUPLED SALTS OF DIVALENT MANGANESE
}

\author{
Gary L. McPHERSON, Kenneth O. DEVANEY, Sarah C. WILLARD \\ Department of Chemistry. Tulane University. New Orleans, Lowisiana 70I18, USA \\ and \\ A.H. FRANCIS \\ Department of Chenistry, Unis ersity of Hichigan, Ann Arbor, Michigan 48107, USA
}

Received 29 August 1979

\begin{abstract}
The emission spectra of several antiferromagnetic complexes of divalent manganese $\left(\mathrm{CsMnBr}_{3}, \mathrm{Rb}_{2} \mathrm{MnCL}_{4}, \mathrm{Cs}_{3} \mathrm{InCl}_{3}\right.$ and $\mathrm{KVInCl}_{3}$ ) which contain rare-earth ion impurities have been studied as a function of temperature. In all cases there appears to be a thermally activated energy migration which often results in an efficient transfer of electronic excitation from the manganese to the rare-earth impurities.
\end{abstract}

\section{Introduction}

A rapid thermally assisted migration of electronic excitation energy has been observed in crystals of the antiferromagnetic manganese salts, $\left(\mathrm{CH}_{3}\right)_{4} \mathrm{NMnCl}_{3}$ (TMMC) and $\mathrm{CsMnBr}_{3}$ - McClure and co-workers determined that the manganese excitation in TMMC begins to migrate above $50 \mathrm{~K}[1]$. At room temperature the migration is extremely rapid with the hopping time for excitons being on the order of $10^{-12} \mathrm{~s}$. They also found that the excitation energy is trapped by iens such as $\mathrm{Co}^{2+}, \mathrm{Ni}^{2+}$, and $\mathrm{Cu}^{2+}$ when these ions are doped into crystals of TMMC. Above $50 \mathrm{~K}$, the intensity of the manganese emission from the doped crystals decreases with increasing temperature as a result of the energy transfer from the manganese to the impurities. No impurity emissions were detected which suggests that the foreign ions behave primarily as nonradiative traps. In $\mathrm{CsMnBr}_{3}$, where the energy migration appears to be qualitatively similar to that of TMMC, emission from impurities has been observed [2] . Crystals of $\mathrm{CsMnBr}_{3}$ doped with neodymium show an emission characteristic of $\mathrm{Nd}^{3+}$ which is stimulated by energy transfer from the manganese. At room temperature the neodymium emission is quite intense, at least an order of magnitude stronger than the emission from manganese. As the doped crystals are cooled the rate of energy transfer decreases so that the manganese emission gains intensity at the expense of the emission from $\mathrm{Nd}^{3+}$.

The observation of an impurity emission is particularly important since it is then possible to directiy monitor the migration and transfer of electronic excitation energy in the doped crystal. This communication describes investigations which explore the generality of the manganese to rare earth energy transfer process. The emission spectra of several antiferromagnetic manganese salts doped with a variety of rare earth ions have been studied. These salts, $\mathrm{CsMnBr}_{3}, \mathrm{Rb}_{2} \mathrm{MnCl}_{4}, \mathrm{CsMnCl}$ and $\mathrm{KMnCl}_{3}$, represent materials in which the predominant magnetic interactions occur in one, two or three dimensions. Energy transfer was observed in all of the salts with $\mathrm{Nd}^{3+}, \mathrm{Ho}^{3+}, \mathrm{Er}^{3+}$. and $\mathrm{Tm}^{3+}$ behaving as radiative traps for the manganese excitation. In these materials the lowest excited state of the divalent manganese, the ${ }^{4} T_{1}$, lies above the ${ }^{6} A_{1}$ ground state by approximately 16000 to $18000 \mathrm{~cm}^{-1}$. As shown in fig1 the rare earth impurities produce a number of emissions in the 9000 to $16000 \mathrm{~cm}^{-1}$ region which arise through a rapid energy transfer in the doped crystals. Crystals doped with $\mathrm{Pr}^{3+}$ and $\mathrm{Eu}^{3+}$ were also studied; 


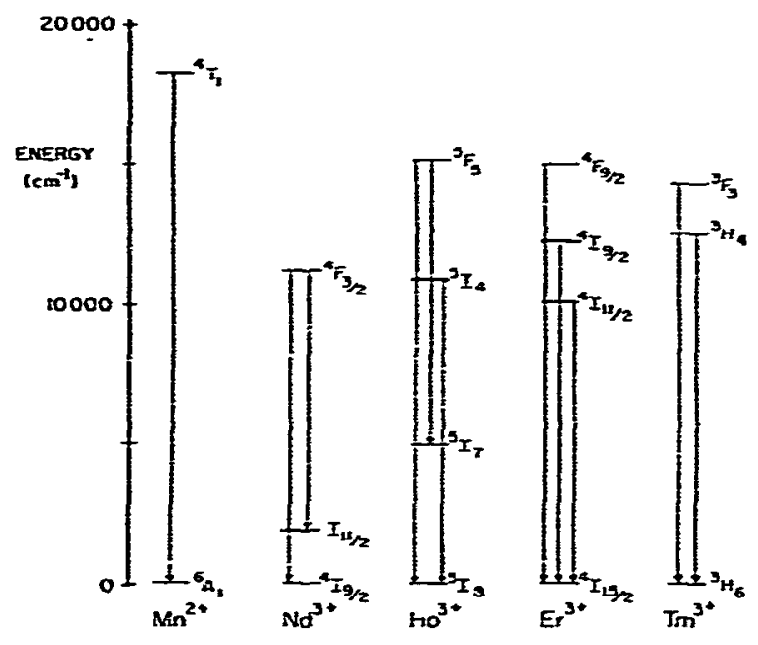

Fig- 1. Energy level dingram showing the rare earth transitions which have been identitied in the emission spectra of the doped manganese salts.

however, no rare earth emissions were detected between 9000 and $16000 \mathrm{~cm}^{-1}$.

Although there are noticeable differences between the salts, the migration and transfer of the manganese excitation energy conforms to the general pattern observed in $\mathrm{TMMC}_{\mathrm{M}}$ and $\mathrm{CsMnBr}_{3}$. It appears that in all of the salts, energy transfer requires some type of thermal activation. At high temperatures (above $200 \mathrm{~K}$ ) the energy transfer between the divalent manganese and the rare earth impurities is quite rapid and of ten very efficient. Fig. 2 shows the emission and excitation spectra of a $\mathrm{Rb}_{2} \mathrm{MnCl}_{4}$ crystal doped with $\mathrm{Tm}^{3+}$ and recorded at room temperature. The behavior of this crystal is typical of most of the doped crystals above $200 \mathrm{~K}$.

The emission spectrum is characteristic of the rare earth while the excitation spectrum shows a close correspondence to the absorption spectrum of the pure manganese salt. As the doped crystals are cooled the rate of energy transfer decreases and the intensity of the rare earth emission begins to diminish. Eventually the rare earth emissions become very $w$ eak as the manganese excitation is effectively localized. During this process the intensity of the manganese emissicn increases dramatically. The following sections contain brief descriptions of each of the manganese salts used in this study.
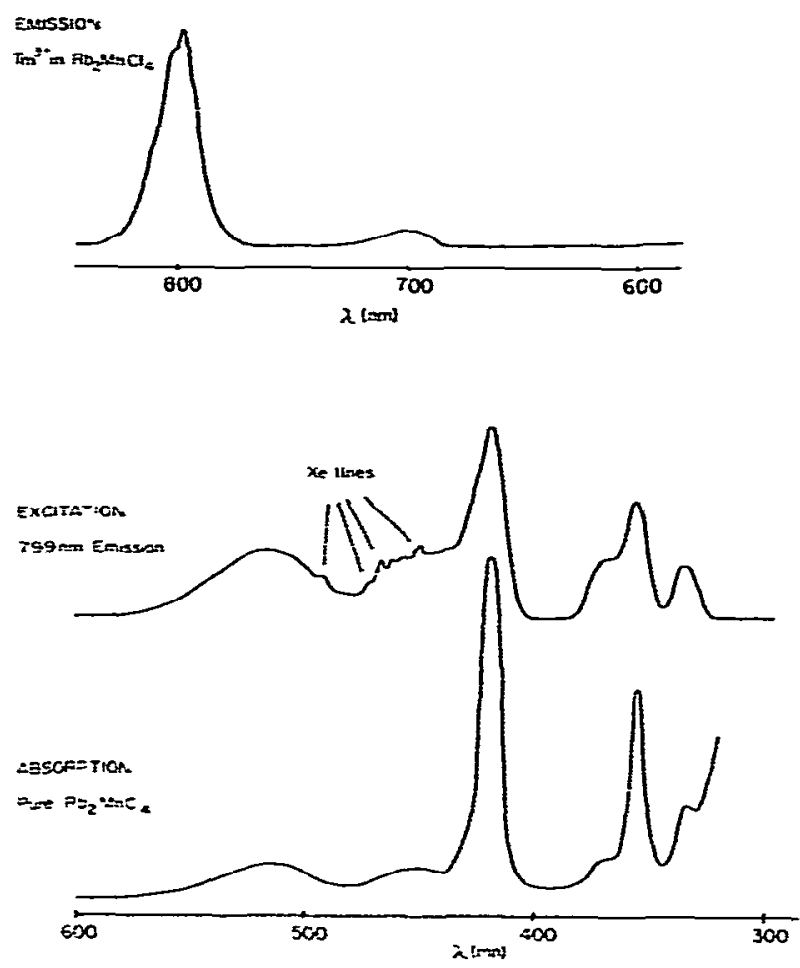

Fig-2. Emisston and excitation spectra of a $\mathrm{Rb}_{2} \mathrm{MnCl}$ crystsl doped with $\mathrm{Tm}^{3+}$ recorded at room temperature. The intense emission at $799 \mathrm{~nm}$ corresponds to the ${ }^{3} \mathrm{H}_{4} \rightarrow{ }^{3} \mathrm{H}_{6}$ transition of $\mathrm{Tm}^{3+}$ while the ueaker feature at $700 \mathrm{~nm}$ results from the ${ }^{3} \mathrm{~F}_{3} \rightarrow{ }^{3} \mathrm{H}_{6}$ transition. 7 he excitation spectrum $\mathrm{u}_{3}$ as obtained by monitoring the $\mathrm{Tm}^{3+}$ emission at $799 \mathrm{~nm}$. The room temperature absorption spectrum of pure $\mathrm{Rb}_{2} \mathrm{MnCl}_{4}$ is included for comparison.

\section{2. $\mathrm{CsMnBr}_{3}$}

Diffraction studies show that $\mathrm{CsMnBr}_{3}$ adopts a hexagonal structure isomorphous with $\mathrm{CsNiCl}_{3}$ [3]. In this structure, the $\left[\mathrm{MnBr}_{6}\right]^{4-}$ octahedra share opposite faces to form infinite linear chains which have the stoichiometry, $\left[\mathrm{MnBr}_{3}^{-}\right]_{n}$. Magnetic susceptibility and neutron scattering studies indicate that $\mathrm{CsMnBr}_{3}$ is a quasione-dimensional antiferromagnet $[4,5]$. The intrachain interaction is about $7 \mathrm{~cm}^{-1}$ which is roughiy 500 times Breater than the interchain coupling. It appears that unless small monovalent ions such as $\mathrm{Li}^{+}$are present trivalent ions tend to cluster in pairs when introduced 
as impurities into crystals which adopt the $\mathrm{CsNiCl}_{3}$ structure [6-8]. Crystals of $\mathrm{CsMnBr}_{3}$ doped with $\mathrm{Nd}^{3+}$ and $\mathrm{Li}^{+}$were studied along with crystals containing only $\mathrm{Nd}^{3+}$. The energy transfer seems to be similar in both cases. Crystals containing $\mathrm{Er}^{3+}$ and $\mathrm{Tm}^{3+}$ show intense rare earth emissions (which indicates that these ions are effective traps for the manganese excitation. In contrast, samples doped with $\mathrm{Ho}^{3+}$ show no rare earth emission. The reason for this is not clear. since $\mathrm{Ho}^{3+}$ emissions are observed in the other manganese salts. The behavior of the emission spectrum as a function of temperature depends to some extent on which rare earth is present in the doped crystal. In general. however, it appears that the rate of energy transfer begins to diminish below $100 \mathrm{~K}$. At $30 \mathrm{~K}$ there is little evidence of energy transfer in any of the samples.

\section{3. $\mathrm{Rb}_{2} \mathrm{MnCl}_{4}$}

The sult, $\mathrm{Rb}_{2} \mathrm{MnCl}_{4}$, crystallizes in a layered structure isomorphous with $\mathrm{K}_{2} \mathrm{NiF}_{4}$ [9]. The naterial is reported to behave as a two-dimensional antiferromagnet with an inplane interaction of approximately $4 \mathrm{~cm}^{-1}$ [10,11]. The magnetic susceptibulity passes through a maximum dround $100 \mathrm{~K}$. Crystals doped with $\mathrm{Nd}^{3+}$. $\mathrm{Ho}^{3+}, \mathrm{Er}^{3+}$, and $\mathrm{Tm}^{3+}$ produce intense rare earth emissions which indicates an effective energy transfer. There is not much evidence of a decrease in energy transfer until the doped crystals are cooled below $70 \mathrm{~K}$. In some samples there is significant transfer even when the temperature is less than $30 \mathrm{~K}$. The intensity of the manganese emission increases by more than an order of magnitude between $70 \mathrm{~K}$ and $30 \mathrm{~K}$. The temperature dependence of the manganese emission from the doped crystals is quite similar to that reported for pure $\mathrm{Rb}_{2} \mathrm{MnCl}_{4}$ [12] .

\section{4. $\mathrm{CsMnCl}_{3}$ and $\mathrm{KMnCl}_{3}$}

There have been several structural investigations of $\mathrm{CsMnCl}_{3}[13-15]$. The material adopts a hexagonal lattice which contains linear $\left[\mathrm{Mn}_{3} \mathrm{Cl}_{12}\right]^{6-}$ units compossed of three $\left[\mathrm{MnCl}_{6}\right]^{4-}$ octahedra sharing faces. These trimeric units share corners to form a threedimensional array. The lattice constants of $\mathrm{KMnCl}_{3}$ suggest that the salt is a tetragonal perovskite at room temperature [16]-Above $731 \mathrm{~K} \mathrm{KMnCl}_{3}$ is cubic. The perovskite structure can be described as a three-dimensional array of $\left[\mathrm{MnCl}_{6}\right]^{4-}$ octahedra sharing corners. In both materials the magnetic interactions would be expected to be three dimensional. It appears that a three-dimensional antiferromagnetic ordering occurs in both salts $[13,17,18]$. The Neel temperatures for $\mathrm{CsMnCl}_{3}$ and $\mathrm{KMnCl}_{3}$ are $69 \mathrm{~K}$ and $100 \mathrm{~K}$, respectively. Rare earth emissions are observed in crystals of both saits doped with $\mathrm{Nd}^{3+}, \mathrm{Ho}^{3+}, \mathrm{Er}^{3+}$, and $\mathrm{Tm}^{3+}$, although the emission from $\mathrm{Ho}^{3+}$ in $\mathrm{CsMnCl}_{3}$ is relatively weak. In $\mathrm{CsMnCl}_{3}$ the energy transfer begins to decrease noticeably below $180 \mathrm{~K}$. At $80 \mathrm{~K}$ the rare earth emissions are very weak. The energy transfer in $\mathrm{KMnCl}_{3}$ persists to around $120 \mathrm{~K}$. It diminishes steadily until the transfer is quite weak at $50 \mathrm{~K}$. In neither salt is there a dramatic change when the temperature passes through the Néel point. Like $\mathrm{Rb}_{2} \mathrm{MnCl}_{4}$, the temperature dependence of the manganese emission from the doped crystals closely resembles that reported for pure $\mathrm{CsMnCl}_{3}$ and $\mathrm{KMnCl}_{3}$ [19]. In $\mathrm{CsMnCl}_{3}$ the manganese emission increases dramatically from $200 \mathrm{~K}$ to $100 \mathrm{~K}$. Below $100 \mathrm{~K}$ the intensity is essentially constant. The intensity of the manganese emission from $\mathrm{KMnCl}_{3}$ grows noticeably between $100 \mathrm{~K}$ and $50 \mathrm{~K}$ and remains relatively unchanged below $50 \mathrm{~K}$

\section{Conclusions}

A thermally activated energy migration appears to be a common characteristic of magnetically coupled manganese salts. A variety of rare earth ions can serve as radiative traps for the manganese excitation. Among the salts used in this study, the extensive energy transfer persists to the lowest temperatures in $\mathrm{Rb}_{2} \mathrm{MnCl}_{4}$ and is quenched at the highest temperatures in $\mathrm{CsMnCl}_{3}$. The energy migration and transfer process does not appear to have a dramatic dependence on the dimensionality of the magnetic interactions in the solid.

\section{Acknowledgement}

This work was supported by National Science Foundation Grant CHE-77-12557. 


\section{References}

[1] H. Yammato, DS. MeClure, C. Marzzacco and M. Waldman, Chem. Phys. 22 (1977) 78.

[2] G.L. McPherson and A.H. Francis, Phys. Rev. Letters 41 (1978) 1681 .

(3) J. Goodyear and D.J. Kennedy. Acta Cryst. B2E (1972) 1640.

[4] M. Eibschuth, R C. Sherwood, F.S.L. Hsu and D.E. Cox, in: Magnetism and Magnetic Materials-1972, AIP Conference Proceedings No. 10. Pt. 1, eds. C.D. Graham Jr. and J.J. Rhyne (American Institute of Physics, New York, 1973) p. 684.

[S] W. Breitiing. W. Lehmann. R. W'eber, N. Lehuer and V. Wagner. J. Magn. Magn. Miat. 6 (1977) 113.

[6] G.L. McPherson and L.M. Henling. Phys. Rev. B16 (1977) 1889.

[7] L.SI. Henling and G.L. McPherson. Phys. Rev. BI6 (1977) 4756.

[8] G.L. McPhexson, W. Heung and J.J. Barrazza, J. Am. Chem. Soc. $100(1978) 469$.
[9] J. Goodyear. E.M. Ali and G.A. Steigman, Acta Cryst. B33 (1977) 2932.

[10] A. Epstein, E. Gureuitz, J. Makousky and H. Shaked, Phys. Rer. B2 (1970) 3703.

[11 I H.T. Vitteveen, J. Solid State Chem. 11 (1974) 245.

[12] M. Kestigian and W.W. Holloway Jr., Phys. Stat. Sol. A 6 (1971) $\mathrm{k} 19$.

[13] M. Melamud, J. Makovsky and H. Shaked, Phys. Rev. B3 (1971) 3872 .

[14] J. Goody ear and D.J. Kennedy, Acta Cryst. B29 (1973) 744.

[15] T. Li.G.D. Stucky and G.L. McPherson, Acta Cryst. B29 (1973) 1330 .

[16] W.J. Kroft, M. Kestigian and F.D. Leipziger. Inorg- Chem. 4 (1965) 423.

[17] R.W. Kedzie, J.R. Shane, M - Kestigian and W.J. Croft, J. Appl. Phys, 36 (1965) 1195.

[18] C.N. Owston, Brit. J. Appl. Phys, 1 (1968) 1930

[19] W.W. Holloway and M. Kestigian, Phys. Letters 29A (1969) 709. 